\title{
Physical Examination Abnormal Finding
}

National Cancer Institute

\section{Source}

National Cancer Institute. Physical Examination Abnormal Finding. NCI Thesaurus. Code C83023.

An indication or description of any abnormal findings as a result of a physical examination. 